\title{
The Origin of Chylomicron Phosphatidylcholine in the Rat
}

\author{
Charles M. Mansbach, II \\ From the Veterans Administration Hospital and the Department of Medicine, Division of \\ Gastroenterology, Duke University Medical Center, Durham, North Carolina 27710
}

A B S TRACT This study investigates the pathways of origin of chylomicron phosphatidylcholine (PC) using a lymph- and bile-fistulated rat infused with a stabilized triolein emulsion. $\left[{ }^{14} \mathrm{C}\right.$-glycerol $] \mathrm{PC}$ was used to evaluate chylomicron PC generated by lyso PC acyltransferase. The percentage of chylomicron PC derived from the PC infused was directly proportional to the PC concentration in the infusate. When the infusate PC concentration was $10 \mathrm{mM}$, essentially all the chylomicron PC was derived therefrom at $4-6 \mathrm{~h}$ of infusion. Incorporation of the radiolabel was not found to be as great in the lymph subnatant $\mathrm{PC}$ as in chylomicron $\mathrm{PC}$, suggesting that chylomicron and lymph subnatant PC might be supplied from different PC precursor pools.

${ }^{32} \mathrm{P}_{\mathrm{i}}$ was infused into similarly prepared rats to judge chylomicron PC synthesized from de novo sources. In these experiments it was found that the percentage of chylomicron PC derived from de novo synthesis was inversely related to the PC concentration of the infusate. This suggests that exogenously infused PC inhibits de novo PC synthesis.

When $\left[{ }^{32} \mathrm{P}\right]$ rat bile PC was infused with $\left[{ }^{14} \mathrm{C}\right.$ glycerol]potato PC, the bile PC was preferred as a chylomicron precursor despite the greater similarity of the saturated fatty acids of potato PC to those of chylomicron PC. When the saturated fatty acids of bile and chylomicron PC were compared, chylomicron PC was significantly richer in stearate, suggesting extensive enterocyte modification of the saturated fatty acids of bile PC.

This work was presented, in part, at the meeting of the Southern Society of Clinical Investigation in New Orleans, La. in January 1976 and at the meeting of the American Federation for Clinical Research in Atlantic City, N. J. in May 1976.

Received for publication 22 July 1976 and in revised form 14 April 1977.

\section{INTRODUCTION}

Although the triacylglycerol (TG):phosphatidylcholine $(\mathrm{PC})^{1}$ molar ratio in chylomicrons is on the order of $20 / 1$ (1), all of the PC is found in the so-called membranous portion of the chylomicron (1). The function of this "covering" is to establish thermodynamic stability to the chylomicron particle so that oiling out of the TG core does not occur. PC is ideally suited to this function of the membrane being classified as a swelling amphipath (2). Although the importance of adequate PC synthesis for TG transport from the intestine has not been conclusively demonstrated, recent evidence points to a crucial role of $\mathrm{PC}$ in chylomicron formation (3).

Previous studies, in conjunction with the known enzyme complement in the gut in regard to PC synthesis, have established that both de novo synthesized $(4,5)$ and lyso PC-derived PC $(6,7)$ might provide chylomicron PC. Circumstantial evidence has been generated by biochemical data that the lyso PC-dependent pathway is the prefered pathway of chylomicron PC synthesis. This evidence may be summarized as follows. The specific activity of lyso PC acyltransferase was found to conform to the known physiologic site of lipid absorption (8); that is its specific activity was greatest in the villous tips of the proximal intestine. Cholinephosphotransferase, which provides de novo synthesized PC, did not. The specific activity of lyso PC acyltransferase was increased to a greater degree than that of cholinephosphotransferase on lipid feeding (9). Lyso PC acyltransferase closely paralleled the specific activity relationships of diacylglycerol acyltransferase, the last

${ }^{1}$ Abbreviations used in this paper: CDP, choline-dependent pathway; GLC, gas-liquid chromatography; PC, phosphatidylcholine; TG, triacylglycerol; TLC, thin-layer chromatography. 
enzyme of the TG synthetic pathway, both in its intestinal localization and in its response to lipid feeding (8-10). Lastly, diacylglycerol acyltransferase and lyso PC acyltransferase were more evenly distributed between the rough and smooth endoplasmic reticulum than cholinephosphotransferase which was more localized to the rough portion (11). Electron microscopic observations clearly place absorbed dietary lipid within the smooth endoplasmic reticulum (12).

The present study was designed to quantitate the importance of both of these pathways of PC synthesis to chylomicron PC formation in an in vivo model under conditions where large amounts of TG were required to be transported from the gut. These studies would thus test the hypothesis that lyso PC acyltransferase is the preferred pathway of chylomicron PC synthesis.

\section{METHODS}

Animal preparation. Male Sprague-Dawley rats weighing 260-350 g received, on the day before an experiment, three cannulae. A PE-50 cannula (Clay Adams Inc., Parsippany, N. J.) was placed in the main intestinal lymphatic (13). A PE-50 cannula was placed in the duodenum $1 \mathrm{~cm}$ proximal to the entry of the common bile duct and advanced $2.5 \mathrm{~cm}$ distally. A third cannula (PE-10) was placed in the proximal common bile duct. All cannulae were exteriorized through the incision, the abdomen closed in two layers and the rat placed in a restraining cage (Plas-Labs, Lansing, Mich.). The rat was infused ovemight with $0.15 \mathrm{M} \mathrm{NaCl}$ through the duodenal cannula with a constant infusion pump (Harvard Apparatus Co., Inc., Millis, Mass.) at a rate of $4.5 \mathrm{ml} / \mathrm{h}$. No food was offered and heparin was not used except to wet the inside of the lymph cannula on its insertion. The next morning, the infusion was changed to a stable TG emulsion which was infused at $4.5 \mathrm{ml} / \mathrm{h}$. The composition of the emulsion was calculated to give high uptake rates of hydrolyzed lipid by the intestinal mucosa. The emulsion contained gum acacia, $10 \mathrm{~g} / \mathrm{dl}$; taurocholate (Calbiochem, San Diego, Calif.), $20 \mathrm{mM}$; triolein (Sigma Chemical Co., St Louis, Mo.), $72 \mathrm{mM}$; Tris buffer (Sigma Chemical Co.) pH 7.0, $100 \mathrm{mM}$; and $\left[{ }^{14} \mathrm{C}\right.$-glycerol $] \mathrm{PC}\left(93-180 \times 10^{3} \mathrm{dpm} /\right.$ $\mu \mathrm{mol}$ ), $5-10 \times 10^{3} \mathrm{dpm} / \mathrm{ml}$ infusate or ${ }^{32} \mathrm{P}_{\mathrm{i}}$ (New England Nuclear, Boston Mass.), 1-2 $\times 10^{5} \mathrm{cpm} / \mathrm{ml}$ infusate. PC derived from egg yolk (8) was added so that its final concentration was increased stepwise from 0 to $10 \mathrm{mM}$. A different rat was used for each PC concentration infused. The PC, which was dissolved in chloroform, was placed in a 50-ml beaker and the chloroform evaporated under a stream of $\mathrm{N}_{2}$. The rest of the infusate components were added and the mixture sonified (Branson Sonic Power Co., Danbury, Conn.), three times for 1.5-2 min while the beaker was immersed in ice water. The white infusate was agitated by hand every $30 \mathrm{~min}$ during the infusion to insure continued homogeneity. Lymph and bile were separately collected in calibrated centrifuge tubes immersed in ice in 2 -h increments for $6 \mathrm{~h}$. The volume of lymph and bile was recorded and the lymph defibrinated with a wooden applicator stick. The lymph was then centrifuged at $8 \times 10^{8} \mathrm{~g}$-min at $4^{\circ} \mathrm{C}$ in a SW-50L rotor in a Beckman L2-65B centrifuge (Beckman Instruments, Inc., Spinco Div., Palo Alto, Calif.) to insure the floatation of all the chylomicrons. The chylomicrons were harvested with a tube slicer and the subnatant, clear lymph was also collected. Electrophoresis of the chylomicron fraction on agarose film strips (laboratory of Dr. Steven Quarfordt, Duke University Medical Center), showed no very low density lipoproteins even when overloaded with chylomicrons. The lymph subnatant was not further characterized as to its lipoprotein composition. The chylomicrons and lymph subnatant were frozen at $-20^{\circ} \mathrm{C}$ until analyzed. Samples, in triplicate, of the infusate were also frozen.

Experiments in which the contribution of free glycerol to chylomicron PC synthesis was determined were performed in three rats as described except that $\left[{ }^{14} \mathrm{C}\right]$ glycerol (New England Nuclear; $8.3 \times 10^{5} \mathrm{cpm} / \mathrm{ml}$ infusate) was infused; no PC was incorporated into the infusate.

Histologic examination of the intestine at the completion of the experiment showed essentially a normal intestinal mucosa except for mild hydropic changes in the villous tips which may have represented absorbed lipid.

To estimate the absorption of ${ }^{32} \mathrm{P}_{\mathrm{i}}$ and triolein in different parts of the small intestine, rats were provided with a duodenal cannula through a midline incision. The intestine was divided more distally and the distal end was tied off. A PE-320 tube was inserted into the proximal end. The intestine was flushed with $0.15 \mathrm{M} \mathrm{NaCl}$ until the wash was clear and the abdomen closed. The rat was placed in a restraining cage and perfused with $0.15 \mathrm{M} \mathrm{NaCl}$ until awake. An infusion was then started with an emulsion as described containing PC $2 \mathrm{mM}$, $\left[{ }^{3} \mathrm{H}\right.$-oleate]triolein (Amersham/Searle Corp., Arlington Heights, Ill.), $5 \times 10^{5} \mathrm{cpm} / \mathrm{ml}$, and ${ }^{32} \mathrm{P}_{1}$ $\left(5 \times 10^{5} \mathrm{cpm} / \mathrm{ml}\right)$. The effluent from the cannula was collected on ice in hourly increments for $6 \mathrm{~h}$. At the conclusion of the experiment the animal was killed with an overdose of pentobarbital sodium and the total small intestine removed. The length of the gut from the pylorus to the cannula was measured as well as the length of the distal portion from the closed end to the ileocecal valve. The total length was determined by addition and the proportion of the total gut perfused determined by dividing the length of the perfused segment by the total length of the gut. The gut contents were aggitated and a $0.1-\mathrm{ml}$ aliquot in duplicate was placed in a counting vial for the direct determination of radioactivity.

When estimation of the total gut "acid-soluble" $\mathrm{PO}_{4}=$ was required, rats received a duodenal and common bile duct cannula. On recovery from anesthesia, they were perfused with $0.15 \mathrm{M} \mathrm{NaCl}$ at $4.5 \mathrm{ml} / \mathrm{h}$ until the next morning. An infusion was then started which contained the triolein emulsion as previously and either 0 (five rats) or $10 \mathrm{mM}$ PC (five rats). At the end of $6 \mathrm{~h}$ of perfusion the rat was sacrificed by an overdose of pentobarbital sodium and the gut rapidly removed to a beaker containing iced saline. The gut contents were washed with $0.15 \mathrm{M} \mathrm{NaCl}$ at $2^{\circ} \mathrm{C}$ and the mucosa exposed and scraped down to the level of the crypts (8). The mucosal scrapings were collected in iced $10 \%$ TCA and homogenized. The TCA-precipitable material was pelleted by centrifugation at $5.40 \times 10^{5} \mathrm{~g}$-min in a Sorvall RC 2-B centrifuge (Ivan Sorvall Inc., Norwalk, Conn.) at $4^{\circ} \mathrm{C}$. The clear supernate was decanted, its volume measured, and $0.1 \mathrm{ml}$ in duplicate obtained for $\mathrm{PO}_{4}=$ assay and radioactivity.

Experiments to study the effect of PC perfusion on mucosal ${ }^{P C}{ }^{32} \mathrm{P}$ specific activity were similarly performed except that ${ }^{32} \mathrm{P}_{1}\left(3 \times 10^{5} \mathrm{cpm} / \mathrm{ml}\right)$ was incorporated into the perfusate which contained triolein plus either 0 or $10 \mathrm{mM}$ PC. Samples of the homogenized mucosa were frozen for future determination of PC specific activity.

To determine the percentage of infused triolein and PC absorbed during the $6 \mathrm{~h}$ of perfusion and the relative 
rates of absorption of triolein and PC, six rats prepared with common bile duct and duodenal cannulae were perfused overnight with $0.15 \mathrm{NaCl}$ at $4.5 \mathrm{ml} / \mathrm{h}$. The next morning a triolein infusion containing $5 \mathrm{mM} \mathrm{PC},\left[{ }^{3} \mathrm{H}\right]$ triolein $\left(1.17 \times 10^{5}\right.$ $\mathrm{cpm} / \mathrm{ml})$, and either $\left[{ }^{32} \mathrm{P}\right]$ rat bile PC $\left(1.3 \times 10^{5} \mathrm{cpm} / \mathrm{ml}\right)$ or $\left[{ }^{14} \mathrm{C}\right.$-glycerol $]$ potato $\mathrm{PC}(1,500 \mathrm{cpm} / \mathrm{ml})$ was perfused at 4.5 $\mathrm{ml} / \mathrm{h}$ for $6 \mathrm{~h}$. The animal was sacrificed by an overdose of pentobarbital sodium and the abdomen opened. Clamps were placed at the pylorus and ileocecal junction and the intervening small bowel was divided into quarters by silk ties. The intestine was removed between ligatures and its luminal contents rinsed into separate test tubes for each one-fourth gut and the mucosa removed by scraping. The gastric and cecal contents were separately collected and the entire colon was removed and homogenized. The radioactivity of each sample was then differentially obtained. The percentage of each radionuclide absorbed was determined by subtracting the radioactivity recovered in the gastric, small bowel and cecal luminal contents plus the colon from the total radioactivity of the radionuclide infused. The relative rates of absorption of triolein and the two types of PC were determined by comparing the isotopic ratio of the infused radionuclides $\left({ }^{32} \mathrm{P}:{ }^{3} \mathrm{H}\right.$ or ${ }^{14} \mathrm{C}$ : $\left.{ }^{3} \mathrm{H}\right)$ to the isotopic ratio of the radionuclides recovered from the lumen of each quarter of the small bowel.

The amount of free $\left[{ }^{14} \mathrm{C}\right]$ glycerol generated within the intestinal lumen was estimated by determining the counts per minute in the aqueous-methanolic phase of an extract (14) of the intestinal luminal contents as compared to those counts per minute remaining in the organic phase when $\left[{ }^{14} \mathrm{C}\right]$ glycerol PC was incorporated in the triolein emulsion.

When the isolation of small amounts of bile PC was required, rats were provided with a common bile duct and duodenal cannula as before. They were infused with $0.15 \mathrm{M}$ $\mathrm{NaCl}$ at $4.5 \mathrm{ml} / \mathrm{h}$ while the bile was collected on ice. When larger amounts were needed, the rat was infused with $10 \mathrm{mM}$ taurocholate and the bile collected with $5 \mathrm{mM}$ EDTA.

Analytical procedures. Lipids were extracted by the method of Folch et al. (14) and partitioned with $4 \mathrm{ml} \mathrm{H}_{2} \mathrm{O}$. The chloroform phase was dried under a stream of $\mathrm{N}_{2}$ and the lipids taken up in $0.5 \mathrm{ml}$ chloroform: methanol $2: 1$, vol: vol. The phospholipids were separated by thin-layer chromatography (TLC) (15) and the PC spots identified by reference to concurrently run standards after exposure to $I_{2}$ vapors. The PC spots were scraped off the plate into counting vials for determination of radioactivity (8) or into test tubes for the quantitative determination of PC (15). PC recovery was $70 \%$. Neutral lipids were separated by TLC with hexane, diethyl ether, acetic acid, and methanol (80:20:2:6, vol:vol). TG was identified by the use of standards and the ester bonds quantitated by the method of Snyder and Stephens (16). When the constituent fatty acids of PC were determined, the PC standards, run on the outside lanes of the TLC plates, were identified under ultraviolet light after spraying only these lanes with $2^{\prime} 7^{\prime}$ dichlorofluorescein. Sample PC spots were then scraped into test tubes and the TLC plate exposed to $I_{2}$ vapors to be certain that the PC spots had been removed. The PC was extracted from the silica gel twice with 3-ml portions of chloroform:methanol 1:1, vol:vol. The solvent was evaporated under a stream of $\mathrm{N}_{2}$ and the PC taken up in $1 \mathrm{ml}$ of chloroform. $2 \mathrm{ml}$ of $2 \%$ sulfuric acid in methanol was added, the test tube sealed under $\mathrm{N}_{2}$ and put in a boiling water bath for $2 \mathrm{~h} .5 \mathrm{ml}$ petroleum ether (boiling point $60-70^{\circ} \mathrm{C}$ ) was used to extract the methyl esters of the fatty acids. The solvent was dehydrated with $\mathrm{Na}_{2} \mathrm{SO}_{4}$ and evaporated to dryness under $\mathrm{N}_{2}$. The lipids were taken up in $0.5 \mathrm{ml}$ petroleum ether and 1 grain of hydroquinone was added. The composition of the fatty acid esters was then determined by gas-liquid chromatography (GLC) with a Hewlett-Packard 5700 A programable gas chromatograph (Hewlett-Packard Co., Palo Alto, Calif.) equipped with a $\mathrm{H}_{2}$ flame detector and an electronic integrator. The 6-foot column was packed with $10 \%$ phosphate stabilized diethylene glycol succinate polyester on 80/100 Supelcoport (Supelco, Inc., Bellefonte, Penn.). The injection and detector temperatures were $250^{\circ} \mathrm{C}$; the column was kept isothermally at $190^{\circ} \mathrm{C} . \mathrm{N}_{2}$ was the carrier gas. The unsaturated fatty acids were identified by hydrogenation and by ozonolysis followed by reduction, using triphenylphosphane. (17) The GLC was performed through the courtesy of Dr. Daniel Menzel, Duke University Medical Center.

TCA-soluble $\mathrm{PO}_{4}=$ was assayed as for $\mathrm{PC} \mathrm{PO}_{4}=(15)$. The TCA utilized was found to give an absorbance near to that of water.

Radioactivity was determined on a Packard model 3390 liquid scintillation spectrometer (Packard Instrument Co., Inc., Downers Grove, Ill.). Counts per minute were converted to disintegrations per minute by the use of a series of quenched standards. $0.1 \mathrm{ml}$ of infusate was counted in triplicate with a toluene-based scintillation cocktail combined 2:1 (vol:vol) with Triton X 100 (Packard Instrument Co., Inc.). The radioactivity of TLC-separated phospholipids was determined as before (18). When ${ }^{32} \mathrm{P}_{\mathrm{i}}$ was used, infusate and $P C$ radioactivity was always determined simultaneously. When ${ }^{32} \mathrm{P}$ and ${ }^{3} \mathrm{H}$ radioactivity was present in the same sample, the gain on the spectrometer was set such that there was an $8 \%$ spillover of ${ }^{32} \mathrm{P}$ into the ${ }^{3} \mathrm{H}$ channel and a $4 \%$ spillover of ${ }^{3} \mathrm{H}$ into the ${ }^{32} \mathrm{P}$ channel.

Calculations. The percentage of lymph PC derived from infusate PC was calculated by dividing the specific activity of the lymph PC by the specific activity of the infused $\mathrm{PC}$ when $\left[{ }^{14} \mathrm{C}\right.$-glycerol]PC was the infused lymph PC precursor. When ${ }^{32} \mathrm{P}_{\mathrm{i}}$ or $\left[{ }^{14} \mathrm{C}\right]$ glycerol was the infused $\mathrm{PC}$ radiolabeled precursor, the counts per minute per milliliter of infused ${ }^{32} \mathrm{P}_{\mathrm{i}}$ or ${ }^{14} \mathrm{C}$ was used as the divisor. Regression lines were calculated by the least squares method on an IBM 1130 computer (IBM Corp., White Plains, N. Y.). The computer was also used to calculate the significance of the difference between the slopes of regression lines and to test the significance between data by Student's $t$ test for unpaired data.

Substrate preparations. $\left[{ }^{14} \mathrm{C}\right.$ glycerol]PC was prepared by the method of Galliard (19) using $\left[{ }^{14} \mathrm{C}\right]$ glycerol as the radioactive substrate and Kennebec potatoes. The product was purified by silicic acid chromatography (20) and gave a single spot on TLC (15). The position of the radiolabel was verified by two methods. The acyl groups of the parent compound were removed by prolonged alkaline hydrolysis. All the radioactivity remained in the aqueous phase after petroleum ether extraction, both before and after its acidification. Secondly, the parent compound was exposed to phospholipase C (Clostridium welchii, Sigma Chemical Co.). $97 \%$ of the radioactive isolated product migrated as diacylglycerol on TLC. Ovo PC was prepared as previously described (8) and finally purified by silicic acid chromatography $(20)$. $\left[{ }^{32} \mathrm{P}\right]$ Bile $\mathrm{PC}$ was prepared by the intraperitoneal injection of $2.5 \mathrm{mCi}^{32} \mathrm{P}_{\mathrm{i}}$ into a bile duct-fistulated rat. Bile was collected for $18 \mathrm{~h}$ and the PC extracted by the method of Folch et al. (14). It was purified by preparative TLC. When large amounts of potato PC were required, four potatoes (439 $\mathrm{g}$ wet weight) were extracted of their lipid content by the method of Bligh and Dyer (21). The chloroform phase was dried with $\mathrm{Na}_{2} \mathrm{SO}_{4}$ and evaporated in vacuo under $\mathrm{N}_{2}$. The lipids were chromatographed on Bio Sil A 100-200 mesh (Bio-Rad Laboratories, Richmond, 
Calif.) using chloroform to remove neutral lipids, chloroform: methanol 80:20 (vol:vol) to remove cephalins, and chloroform:methanol 1:1 (vol:vol) to elute the PC fraction. The fatty acid composition of the potato lecithin utilized was determined in triplicate. The weight percentages of the major acyl constituents were $16: 0,21 \% ; 18: 0,11 \% ; 18: 2,48 \%$; $18: 3,13 \%$. The taurocholate purity was assessed on TLC (iso-amyl acetate, proprionic acid, n-propanol, $\mathrm{H}_{2} \mathrm{O} ; 45 / 45 /$ $30 / 22, \mathrm{vol} / \mathrm{vol}$ ) and found to give a single spot. The triolein was of practical grade (Sigma Chemical Co.) and was washed repeatedly in ethanol as suggested by Clark et al. (22). On analysis, $96 \%$ of the resultant material was as TG.

\section{RESULTS}

Overnight lymph and bile flow averaged 1.8 and 0.7 $\mathrm{ml} / \mathrm{h}$, respectively. The infusion of the triolein emulsion stimulated the flow of both lymph and bile which averaged $2.5 \pm 0.2 \mathrm{ml} / \mathrm{h}$ and $1.1 \pm 0.1 \mathrm{ml} / \mathrm{h}$, respectively. The volume of lymph collected in each 2-h period provides evidence as to the adequacy of the lymph fistula and the physiologic state of the rats during the experiment. The intestinal luminal concentration of PC when no PC was included in the infusate was $49 \pm 7 \mathrm{nM} / \mathrm{ml}$ (lyso PC concentration: $15 \pm 15 \mathrm{nM} / \mathrm{ml}$ ). Thus, luminal PC was chiefly provided by infusate PC.

Table I shows the quantitative data as regards PC and TG output in the two lymph fractions analyzed. In the chylomicron fraction, the duodenal lipid infusion considerably increased both PC and TG output during each 2 -h period. It would be expected that after $4 \mathrm{~h}$ of infusion, lymphatic TG output would reach a steady state (23). This was confirmed in the present experiments by collecting lymph during an additional $2 \mathrm{~h}$ of infusion in six rats as shown in the Table (hours 6-8). PC output reached near steady-state conditions as well. The PC:TG ratio is consistant with previous data on rat chylomicrons $(1,24)$. The average chylomicron PC:TG ratio when no PC was included in the infusate $(0.073 \pm 0.027)$

TABLE I

Triacylglycerol and Phosphatidylcholine Lymph Output in Rats Infused Intraduodenally with a Triolein Emulsion

\begin{tabular}{lcccc}
\hline & $0-2^{*}$ & $2-4$ & $4-6$ & $6-8$ \\
\cline { 2 - 5 } & & & & \\
\hline $\begin{array}{c}\text { Chylomicrons } \\
\text { Triacylglycerol } \\
\text { output, } \mu \text { mol/2 } h\end{array}$ & $17.2 \pm 4.3 \ddagger$ & $34.6 \pm 6.4$ & $51.9 \pm 9.5$ & $47.2 \pm 11.5$ \\
$\begin{array}{c}\text { Phosphatidylcholine } \\
\text { output, } \mu \text { mol/2 } h\end{array}$ & $1.4 \pm 0.28$ & $2.6 \pm 0.36$ & $3.1 \pm 0.41$ & $3.3 \pm 0.7$ \\
$\begin{array}{c}\text { Lymph subnate } \$ \\
\text { Triacylglycerol } \\
\text { output, } \mu \text { mol/2 } h\end{array}$ & $2.2 \pm 0.47$ & $3.1 \pm 0.50$ & $2.4 \pm 0.51$ & ND" \\
$\begin{array}{c}\text { Phosphatidylcholine } \\
\text { output, } \mu \text { mol/2 } h\end{array}$ & $0.95 \pm 0.12$ & $1.0 \pm 0.13$ & $0.84 \pm 0.11$ & $\mathrm{ND}^{\prime \prime}$ \\
\hline
\end{tabular}

* At time 0 the triglyceride infusion was begun.

I Data is expressed as the mean \pm 1 SEM.

$\$$ Lymph subnate is all the lymph below the chylomicron fraction; see Methods. "ND, not done. was the same as when $10 \mathrm{mM}$ PC was included with the infusate $(0.078 \pm 0.017, P=0.89)$. Of additional interest is that the vast majority of the lymph TG is found in the chylomicron fraction whereas PC is more equally distributed between the chylomicrons and the lipoproteins of the subnate. These more dense lipoproteins responded minimally to the TG infusion.

Fig. 1 displays the percentage of chylomicron PC derived from infusate $\mathrm{PC}$ when $\left[{ }^{14} \mathrm{C}\right.$ glycerol]PC was infused (hours 4-6 of infusion). As shown in the Figure, this percentage increased as the concentration of PC was increased in the infusate. Virtually all of the chylomicron PC was derived from the PC infused when the infusate PC concentration was 10 $\mathrm{mM}$. The regression lines comparing the infusate $\mathrm{PC}$ concentration to the percentage of $\mathrm{PC}$ derived from the infused PC was for hours 0-2: $y=2.96 x+3.32$, $r=0.60$; for hours $2-4: y=7.11 x-0.58, r=0.91$; and for hours 4-6: $y=9.8 x+0.53, r=0.94$.

It should be noted that as the infusion continued, the slopes of the regression lines increased, presumably reflecting progressively more adequate labeling of the enterocyte (mucosal epithelial cells) PC pool.

It is unlikely that free $\left[{ }^{14} \mathrm{C}\right]$ glycerol generated from $\left[{ }^{14} \mathrm{C}\right.$ glycerol]PC contributed significantly to $\left[{ }^{14} \mathrm{C}\right]-$ chylomicron PC. Only $0.61 \pm 0.11 \%$ of chylomicron PC was derived from infused $\left[{ }^{14} \mathrm{C}\right]$ glycerol under conditions which maximized de novo PC synthesis (vide infra). Furthermore, none of the infused $\left[{ }^{14} \mathrm{C}\right.$ glycerol]PC was found in the aqueous phase of gut luminal contents which suggests a minimal liberation of free PC glycerol within the intestinal lumen.

The percentage of lymph subnatant PC calculated in the same way as for chylomicron PC was also determined. However, as shown in Fig. 2, for hours

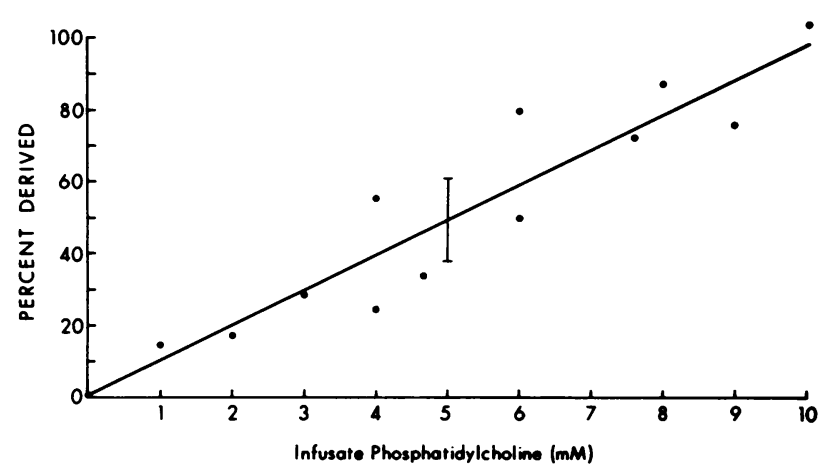

FIGURE 1 The percentage of chylomicron PC derived from the duodenal infusion of $\left[{ }^{14} \mathrm{C}\right.$ glycerol $]$ potato $\mathrm{PC}$. The infusion also contained a stabilized triolein emulsion and the amount of ovo PC indicated on the abscissa. The correlation coefficient is $r=0.94$. The regression line, calculated by the least squares method is shown and its standard error indicated by the verticle bar. Lymph was collected during the 4 th to 6 th $h$ of infusion.

\section{C. M. Mansbach, II}




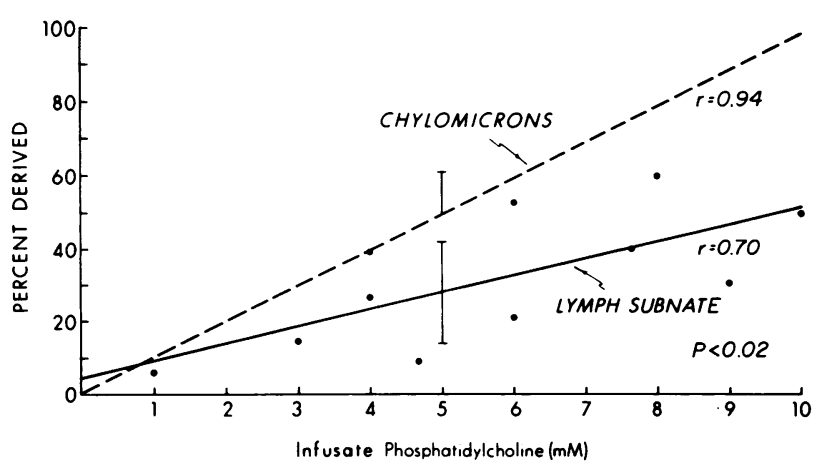

FIGURE 2 The percentage of chylomicron and lymph subnatant PC derived from the duodenal infusion of [ ${ }^{14} \mathrm{C}$ glycerol $]$ potato PC. The rats were infused from hours 4-6 with infusions as in Fig. 1. The dashed line and verticle bar represent the regression line and its standard error for chylomicron PC. The data points, the solid line and verticle bar represent the regression line and its standard error for lymph subnatant PC. The correlation coefficients, $r$, are indicated. The slopes of the two regression lines were significantly different from each other as indicated by the $P$ value.

4-6 of infusion, the slope of the regression line relating infusate $\mathrm{PC}$ concentration to the percentage of lymph subnatant PC derived from it was significantly reduced. These data would suggest that the PC pool(s) from which chylomicron $\mathrm{PC}$ is derived is different from the PC pool(s) supplying subnatant PC and that the subnatant PC precursor pool(s) is less readily labeled with exogenous PC. This might be expected in view of the composition of the subnatant lipoproteins (low, very low, and high density lipoproteins) some of which have a presumably extra intestinal origin.

It is possible that the data depicted in Fig. 2 reflect merely the fact that the subnatant PC pool is more slowly turning over than the chylomicron PC precursor pool although the two pools are the same. This possibility is unlikely as shown by the data displayed in Table II. At each time period during the infusion, the ratio of the percentage of chylomicron to subnatant PC derived from infusate PC was the same. Were the subnatant $P C$ precursor pool turning over more slowly than the chylomicron $\mathrm{PC}$ pool, the ratio should have progressively increased.

TABLE II

The Ratio of Chylomicron Phosphatidylcholine Specific Activity to Lymph Subnatant Phosphatidylcholine Specific Activity

\begin{tabular}{lccc}
\hline & \multicolumn{3}{c}{ Chylomicron/lymph subnate* } \\
\cline { 2 - 4 } & $0-2 \mathrm{~h} \downarrow$ & $0-4 \mathrm{~h}$ & $4-6 \mathrm{~h}$ \\
\hline Radioactive precursor: & & & \\
[ ${ }^{14} \mathrm{C}$ glycerol]phosphatidylcholine & $3.15 \pm 1.46$ & $1.94 \pm 0.38$ & $2.03 \pm 0.22$ \\
Radioactive precursor: ${ }^{32} \mathrm{P}_{\mathrm{t}}$ & $1.80 \pm 0.29$ & $2.01 \pm 0.44$ & $2.00 \pm 0.31$ \\
\hline
\end{tabular}

* Lymph subnate is all the lymph below the chylomicron fraction; see Methods. $\downarrow$ At time 0 the triolein infusion was begun
In considering the data derived from these studies, it is important to know if both of the infused lipids were absorbed equally well along the length of the gut so that the PC pool within the enterocytes would be adequately labeled at the site of triolein absorption. To this point $\left[{ }^{3} \mathrm{H}\right]$ triolein, $\left[{ }^{14} \mathrm{C}\right.$ glycerol $] \mathrm{PC}$, and $\left.{ }^{32} \mathrm{P}\right] \mathrm{PC}$ (vide infra) were utilized to respectively mark lipid absorption. Since both PCs were absorbed at the same rate, the data are considered together. The isotopic ratio of ${ }^{3} \mathrm{H}:{ }^{14} \mathrm{C}\left[{ }^{32} \mathrm{P}\right]$ of the infusate was compared to that recovered from the lumen of the gut in each one-fourth of the intestine. The data (1.2 $\pm 0.04,1.0 \pm 0.15,0.96 \pm 0.14,0.79 \pm 0.11)$ indicate that both triolein and PC were absorbed at nearly the same rates. It is not believed that the modest differences from unity materially affect the interpretation of the data.

However, within the mucosal cells, the isotopic ratio ${ }^{3} \mathrm{H}:{ }^{14} \mathrm{C}\left[{ }^{32} \mathrm{P}\right]$ progressively fell along the length of the intestine $(0.91 \pm 0.19,0.45 \pm 0.06,0.31 \pm 0.04$, $0.26 \pm 0.03$ ) indicating that there is a preferential loss of ${ }^{3} \mathrm{H}$ (oleate) from the mucosal cells in the distal three-fourths gut as compared to PC. This data established that there is no preferential availability of PC for egress from the enterocytes but rather suggests that absorbed PC transport is relatively retarded as compared to TG.

The possibility was considered that labeled PC, absorbed into the vascular space, contributed significantly to the radioactivity of chylomicron PC during the experiment. This was excluded by two findings: (a) That the specific activity of plasma PC was only $6 \%$ of chylomicron PC after $6 \mathrm{~h}$ of perfusion. (b) That chylomicron PC specific activity was only $7 \%$ of serum PC specific activity when radiolabeled PC was infused into the jugular vein during intraduodenal lipid infusions. In both experiments [ $\left.{ }^{32} \mathrm{P}\right] \mathrm{PC}$ was utilized.

By contrast to the data presented in Fig. 1, Fig. 3 shows the data where ${ }^{32} \mathrm{P}_{\mathrm{i}}$ was infused and was the radiolabeled chylomicron PC precursor (hours 4-6 of infusion). ${ }^{32} \mathrm{P}_{\mathrm{i}}$ incorporation was utilized as representing de novo $\mathrm{PC}$ synthesis ultimately via the CDP cholinedependent pathway. In essence the data shown reflects the mirror image of that obtained with $\left[{ }^{14} \mathrm{C}\right.$ glycerol]PC. That is, as the infusate PC concentration was increased, progressively less chylomicron PC was derived from the infused ${ }^{32} \mathrm{P}_{\mathrm{i}}$. The regression lines were for hours 0-2: $y=-0.207 x+1.86, r$ $=-0.81 ;$ for hours 2-4: $y=-0.534 x+5.26, r$ $=-0.93 ;$ and for hours 4-6: $y=-0.848 x+8.7$, $r=-0.98$. It should be noted that the slopes of the regression lines become progressively more negative as the time of infusion is increased suggesting more adequate labeling of the enterocyte $\mathrm{PO}_{4}=$ pool over the infusion period. 


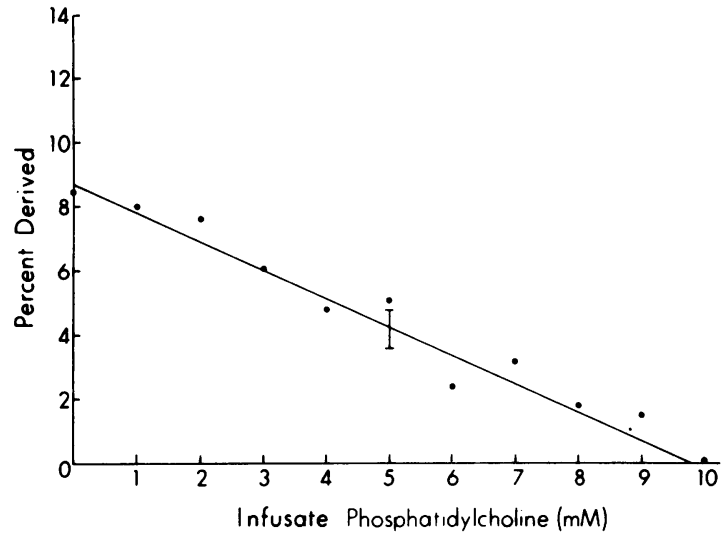

FIgURE 3 The percentage of chylomicron PC derived from the duodenal infusion of ${ }^{32} \mathrm{P}_{\mathrm{i}}$. Lymph was collected during the 4th and 6th $h$ of perfusion as in Fig. 1. The correlation coefficient is $r=-0.98$; the regression line and its standard error are shown. It should be noted that the specific activity of mucosal ${ }^{32} \mathrm{P}$ was $7 \%$ of that infused.

It is possible that at high $\mathrm{PC}$ infusions, the low percentage of chylomicron PC derived from infusate ${ }^{32} \mathrm{P}_{\mathrm{i}}$ was merely due to a large flux of PC under these conditions. This interpretation is rendered less likely by the consideration that $10-\mathrm{mM}$ PC infusions reduced the total ${ }^{32} \mathrm{P}$ counts per minute appearing in the lymph by 30 -fold as compared to infusions containing no PC. An additional experiment was done at each PC concentration and the data was averaged with that shown in Fig. 3.

As further proof of the effect of PC infusions on de novo PC synthesis, six experiments were performed at either 0 or $10 \mathrm{mM} \mathrm{PC}$ infusion with infused ${ }^{32} \mathrm{P}_{\mathrm{i}}$ as the PC precursor. After $6 \mathrm{~h}$ of perfusion, whole intestinal mucosal specific activity was determined. 10-mM PC infusions were found to reduce incorporation of ${ }^{32} \mathrm{P}_{\mathrm{i}}$ into $\mathrm{PC}$ by $45 \pm 7 \%$ as compared to infusions containing no PC. During the PC infusion, total mucosal PC remained nearly the same $(34.0$ $\pm 2.5 \mu \mathrm{mol})$ as when no PC was infused $(29.9 \pm 4.9$ $\mu \mathrm{mol})(P>0.40)$. It should be noted that this reduction of ${ }^{32} \mathrm{P}$ incorporation into mucosal $\mathrm{PC}$ was not as great as when chylomicron $\mathrm{PC}$ is considered again suggesting the possibility of differing mucosal PC pools.

Of further interest is that chylomicron PC again was more readily labeled from exogenous ${ }^{32} \mathrm{P}_{i}$ than was subnatant PC (Table II). This would suggest that de novo synthesized PC is distributed into a pool(s) from which chylomicron PC is preferentially derived. This data also implies that de novo synthesized PC precursor pool(s) for chylomicron and subnatant $\mathrm{PC}$ are different.

In these experiments it is evident that a water soluble radiolabeled precursor $\left({ }^{32} \mathrm{P}_{\mathrm{i}}\right)$ is being used to monitor an event that is dependent on the absorption of amphipathic lipids. Therefore, it is possible that the infused ${ }^{32} \mathrm{P}_{\mathrm{i}}$ and triolein are differentially absorbed. Fig. 4 explores this possibility. It is seen that in the middle portion of the gut, there is preferential absorption of ${ }^{32} \mathrm{P}_{\mathrm{i}}$ in comparison to the $\left[{ }^{3} \mathrm{H}\right]$ triolein concurrently infused. Thus chylomicrons containing de novo synthesized PC transported into the lymph from this portion of the gut would be enriched with ${ }^{32} \mathrm{P}_{\mathrm{i}}$ out of proportion to the TG transported. Since the proximal $60-70 \%$ of the gut was actively absorbing lipid in the current experiments, it is clear that this complication must be taken into account in interpreting the results in a quantitative sense.

The data presented in Fig. 3 may also be interpreted to indicate that the infused ovo PC is broken down either in the gut lumen or enterocyte releasing ${ }^{31} \mathrm{P}_{\mathrm{i}}$ which would dilute the $\mathrm{PO}_{4}=$ pool labeled with ${ }^{32} \mathrm{P}_{\mathrm{i}}$. This thesis is rendered unlikely by the observation that the mucosal acid-soluble $\mathrm{PO}_{4}=$ pool from rats infused with the TG emulsion with either 0 or $10 \mathrm{mM}$ PC added to the infusate was nearly the same, 58.8 \pm 2.1 and $59.5 \pm 3.8 \mu \mathrm{mol} \mathrm{PO}_{4}=$, respectively. In addition the specific activity of mucosal $\mathrm{PO}_{4}{ }^{2}$ as compared to infusate ${ }^{32} \mathrm{P}_{\mathrm{i}}$ was $0.070 \pm 0.015 \mathrm{cpm} / \mathrm{ml}$ when no PC was included in the infusate and $0.065 \pm 0.011$ when $10 \mathrm{mM}$ PC was infused.

Since bile was excluded from the intestine so that intestinal luminal PC content could be more precisely known, the question arises as to whether bile PC might not be a better chylomicron PC precursor than potato PC. This question was examined utilizing two different experiments. In the first experiment $\left[{ }^{32} \mathrm{P}\right]$ bile $\mathrm{PC}$ and $\left[{ }^{14} \mathrm{C}\right]$ potato $\mathrm{PC}$ were infused together with from 0 to $10 \mathrm{mM}$ ovo $\mathrm{PC}$ in eight rats. The isotopic ratio of the chylomicron PC was then compared to the isotopic ratio of the infusate. The data, shown in Table III, indicates that the chylomicron $\mathrm{PC}$ was enriched with ${ }^{32} \mathrm{P}$ (bile $\mathrm{PC}$ ) as compared

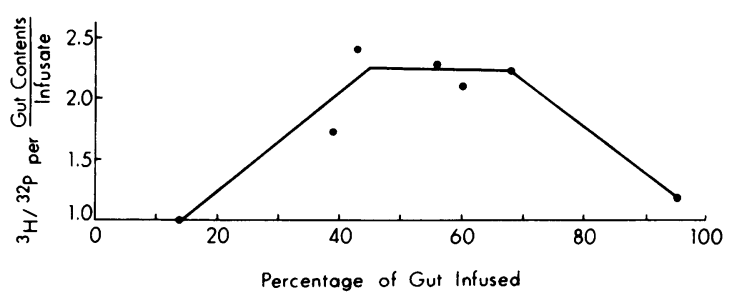

Figure 4 The relative absorption of ${ }^{32} \mathrm{P}_{1}$ and $\left[{ }^{3} \mathrm{H}\right]$ triolein. Rats, whose intestines were cannulated at varying distances from the pylorus as shown, were infused through a proximal duodenal cannula with $\left[{ }^{3} \mathrm{H}\right]$ triolein and ${ }^{32} \mathrm{P}_{1}$ at a known ratio of radioactivity. The luminal content passed into the more distal cannula and the ratio of ${ }^{3} \mathrm{H}:{ }^{32} \mathrm{P}$ determined. By comparing the ${ }^{3} \mathrm{H}:{ }^{32} \mathrm{P}$ ratio in the gut contents to the ratio of the infusate, the absorption of ${ }^{3} \mathrm{H}$ in relation to ${ }^{32} \mathrm{P}$ can be calculated. This ratio should be 1 if both were absorbed at the same rate. 
TABLE III

Comparison of Incorporation of [ $\left.{ }^{32} \mathrm{P}\right]$ Bile Phosphatidylcholine and $\left[{ }^{14} \mathrm{C}\right]$ Potato Phosphatidylcholine into Chylomicron Phosphatidylcholine*

\begin{tabular}{|c|c|c|c|}
\hline & \multicolumn{3}{|c|}{ Hours of infusion } \\
\hline & $0-2$ & $2-4$ & $4-6$ \\
\hline$\frac{\text { Chylomicro }{ }^{32} \mathrm{P}:{ }^{14} \mathrm{C} \ddagger}{\text { Infusate }{ }^{32} \mathrm{P}:{ }^{14} \mathrm{C}}$ & $1.44 \pm 0.12$ & $1.59 \pm 0.12$ & $1.57 \pm 0.041$ \\
\hline$P$ values $\S$ & 0.0028 & 0.0003 & 0.0001 \\
\hline
\end{tabular}

* Bile phosphatidylcholine labeled with ${ }^{32} \mathrm{P}$ was isolated from rats given ${ }^{32} \mathrm{P}_{1}$ intraperitoneally as described in Methods. [ ${ }^{14} \mathrm{C}$ glycerol]phosphatidylcholine was prepared from potatoes incubated with ${ }^{14} \mathrm{C}$ ]glycerol as described in Methods.

I The ratio of bile $\left[{ }^{32} \mathrm{P}\right]$ to potato $\left[{ }^{14} \mathrm{C}\right]$ phosphatidylcholine radioactivity in chylomicron phosphatidylcholine is compared to the ratio of the radiolabeled substrates in the infusate.

$\$$ Significance of differences between isotopic ratios and unity.

to the infusate at each time interval. This data was confirmed in an experiment in which $2 \mathrm{mM}$ bile $\left[{ }^{32} \mathrm{P}\right] \mathrm{PC}$ and $2 \mathrm{mM}$ potato $\left[{ }^{14} \mathrm{C}\right] \mathrm{PC}$ were incorporated into the triolein emulsion and infused into a rat. The ratio of bile- to potato-derived PC in the chylomicron averaged 1.72. This excludes the possibility that the data depicted in Table III was an artifact of the small radioactive mass included in the infusate. The data cannot be explained on the basis of enhanced absorption of the bile PC since both bile and potato PC were equally well absorbed (72 and $71 \%$ of infused PC, respectively), nor on the basis of a differential enrichment of the mucosa with bile PC. The percentage of infused ${ }^{14} \mathrm{C}$ recovered from the mucosa after $6 \mathrm{~h}$ of perfusion for each one-fourth of the intestine was 3.4, 9.1, 8.0, and 1.0. For ${ }^{32} \mathrm{P}$ the percentages were $4.1,9.0,6.5$, and 1.8. In sum, the data would suggest that bile PC was a preferred chylomicron PC precursor as compared to potato PC.

The second experiment examined the fatty acid composition of bile and chylomicron PC. The results are shown in Table IV. It is clear from the table that the predominant saturated fatty acid of bile is palmitate whereas palmitate and stearate are nearly equally present in chylomicron PC. There is, as well, a modest increment in chylomicron PC as compared to bile PC. Since the unsaturated 2-acyl group would be expected to be hydrolyzed during absorption (6), it might be expected that some differences would occur in the unsaturated fatty acids. However, the saturated fatty acids, chiefly esterified at the 1-acyl position of PC (25), are not reported to be hydrolyzed during absorption (6). Therefore, the chylomicronsaturated fatty acids should reflect more closely than the unsaturates its PC of origin. It can be clearly seen from Table IV, however, that despite the data displayed in Table III, the saturated fatty acids of bile PC cannot be the preferred precursor of the saturated fatty acids of chylomicron PC.

\section{DISCUSSION}

The sequential steps in which dietary TG is first hydrolyzed within the intestinal lumen and the TG molecule reformed within the enterocyte preparatory to its transport are well established (26). Its acyl constituents reflect those of the diet (27). The TG is transported from the gut chiefly in chylomicrons of which it forms the major component (1). PC is an additional lipid component of the chylomicron. This compound differs from the neutral lipid in two major respects. Firstly, its location within the chylomicron is at the surface of the lipoprotein rather than within its core (1). Although only a minor constituent of the total particle, it comprises $40-64 \%$ of the membrane which surrounds it (1). Secondly, it is known that the acyl groups of chylomicron PC significantly differ from those present in the diet and remain relatively constant despite large variations in the composition of dietary fatty acids $(1,28)$.

TABLE IV

Fatty Acid Composition of Chylomicron and Bile Phosphatidylcholine

\begin{tabular}{ccccccccc}
\hline & \multicolumn{7}{c}{ Weight, \% } \\
\cline { 2 - 9 } Phosphatidylcholine source* & $10: 0$ & $12: 0$ & $14: 0$ & $16: 0$ & $16: 1$ & $18: 0$ & $18: 1$ & $18: 2$ \\
\hline Chylomicron & 3.7 & 4.4 & 1.9 & 21.7 & Trace & 18.1 & 8.7 & 41.8 \\
& \pm 1.8 & \pm 0.60 & \pm 0.97 & \pm 0.50 & & \pm 0.78 & \pm 0.93 & \pm 1.1 \\
Bile & 2.7 & 3.3 & 2.3 & 38.0 & 2.4 & 7.4 & 9.0 & 35.3 \\
& \pm 0.65 & \pm 0.50 & \pm 0.70 & \pm 0.50 & \pm 0.77 & \pm 0.60 & \pm 0.81 & \pm 1.3 \\
$P$ values $¥$ & 0.65 & 0.18 & 0.73 & 0.0001 & 0.17 & 0.0001 & 0.81 & 0.01 \\
\hline
\end{tabular}

* See Methods for the fatty acid composition of potato phosphatidylcholine.

\$ The $P$ values test the significance of the differences between chylomicron and bile phosphatidylcholine sources for each individual fatty acid. 
The intestine can synthesize PC either de novo $(4,5)$ or from lyso PC $(6,7)$. The de novo synthetic pathway was originally described by Weiss et al. (29) in liver and has been shown to be present in intestine as well ( 8 , 30). This pathway, dependent on the chemical compound "CDP choline", operates at a branch point in diacylglycerol metabolism. The second pathway utilizes 1-acyl lyso PC to which an acyl group is added to form PC. This addition is mediated by lyso PC acyltransferase which also was first described in liver (31) but has been found in intestine as well $(8,32)$. Substrate might be provided by exogenous or biliary PC (33) or serum (34). The purpose of the present experiments was to present data bearing on the quantitative contribution of both PC synthetic pathways toward chylomicron PC synthesis.

To quantitate the contribution of $\mathrm{PC}$ generated by lyso PC acyltransferase to chylomicron $\mathrm{PC},\left[{ }^{14} \mathrm{C}\right.$ glycerol]PC was infused into the duodenum. The results obtained with this radiolabeled PC support the previous in vitro biochemical data $(8-11)$ which had suggested the importance of lyso PC acyltransferase to chylomicron PC synthesis, i.e., under appropriate conditions, all of the chylomicron PC could be calculated to have been derived via this pathway. Furthermore, this data would suggest that the lyso PC-dependent pathway is the preferred pathway of chylomicron PC synthesis and that its quantitative contribution to chylomicron PC is dependent upon substrate availability.

Previous data has not suggested such a major role for this pathway; at maximum $46 \%$ of chylomicron phospholipid has been calculated to be derived from intraluminal PC (6). There are several possible reasons for this difference. $(a)$ The current study used a continuous infusion of lipid rather than a gastric bolus, thus more uniformly labeling intracellular pools. (b) The animals in the present study were bile fistulated such that the intraluminal PC pool was more clearly known and not diluted by bile PC. (c) The mesenteric lymph duct was cannulated in the present study rather than the thoracic duct so that less time was available for phospholipid exchange (35) to occur thus reducing chylomicron specific activity. Furthermore, the lymph evaluated came solely from the intestine. (d) The quantity of PC infused was greater in the present study. (e) Lymph samples were handled separately by time of collection rather than being lumped together. This is important because, as shown, the percentage of chylomicron PC derived from infusate PC increased with time. $(f)$ The position of the radiolabel is also believed to be important. For example, were the radiolabel on the choline moiety, the label might be lost by base exchange (36). A label placed on the 1-acyl moiety might also give confusing data as pointed out in the present study.
However, it is recognized that during digestion in the human, under normal postprandial conditions with an intact biliary system, the PC and lyso PC concentration in the intestinal lumen is $1.5-2.5 \mathrm{mM}$ (15). This would suggest, if the present data is transposable to humans, that under physiologic circumstances the majority of chylomicron PC comes from an alternate synthetic pathway. This pathway is most likely the CDP choline dependent pathway. As shown, when PC was withheld from the TG emulsion infusion, the contribution toward chylomicron PC of de novo synthesized PC was at a maximum and decreased as PC was added to the infusate.

The present studies were performed with high infusate concentrations of TG (37) which would suggest that transport rates in the lymph of PC and TG would also be large. To exclude the possibility that at lower lymphatic TG-PC transport rates a greater proportion of chylomicron PC would be derived from exogenous PC, experiments were performed at infusate TG concentrations $1 / 10$ that routinely used. Preliminary data, in which 1 or $2 \mathrm{mM}$ PC was included in the TG emulsion infusion, are only modestly different than that presented in Fig. 1; 16 and $34 \%$ of the chylomicron PC was derived from that infused. Thus even at low TG transport rates, the majority of chylomicron PC would be expected to be derived from de novo PC synthesis at PC concentrations routinely expected within the intestinal lumen.

It is of interest that the quantity of TG put out into the lymph was the same whether or not PC was included in the TG infusion (data not presented). This would imply that either PC synthetic enzyme, when taken to its physiologic maximum, does not limit TG transport. Furthermore, when examined in a more refined manner, the molar ratio of PC to TG does not change whether or not PC is included in the infusate suggesting that PC can quantitatively be synthesized by either pathway to provide ample PC for TG transport. Were PC to become limiting, then a decrease in the PC:TG ratio would be expected as has previously been described for chylomicrons formed in the distal intestine (3). In sum, this data suggests that either PC synthetic pathway is capable of providing adequate PC to provide for chylomicron synthesis and transport.

Of particular interest in the present work is the reciprocal nature of the regression lines with $\left[{ }^{14} \mathrm{C}\right.$ glycerol ]PC and ${ }^{32} \mathrm{P}_{\mathrm{i}}$ as the chylomicron PC precursors. This suggests that the availability of PC or lyso PC to gut microsomes in some manner negatively influences de novo PC synthesis. The resultant effect of this is to reduce PC synthesis via the CDP cholinedependent pathway which would preserve diacylglycerol for TG rather than PC synthesis. Furthermore, this would be energy conserving. Only two high energy phosphate bonds are utilized to activate fatty 
acid before its esterification to lyso PC for the lyso PC-dependent pathway, whereas five are required if $\mathrm{PC}$ is generated from monoacylglycerol (two to activate the fatty acid esterified at the sn- 1 position, one to form phosphorylcholine from choline, and two to generate CDP choline) or seven if PC is generated from snglycerol 3 phosphate (four to activate two fatty acids and three to fully generate CDP choline).

It is not clear at what point de novo PC synthesis can be controlled. With isolated rat hepatocytes, Sundler and Akesson (37) suggested that phosphorylcholine cytidylyltransferase is important in this regard. This thesis is in part substantiated by studies in developing rat liver (38). However, the concomitant increase in specific activity of both cholinephosphotransferase and the cytidylyltransferase makes a clear interpretation of this data impossible. Alternatively, the specific activity of cholinephosphotransferase relative to diacylglycerol acyltransferase has been proposed as a means of regulating the distribution of microsomal bound diacylglycerol into either PC or TG synthetic pathways (39). It is unlikely that the back reaction of cholinephosphotransferase (40) plays a regulatory role.

It is equally possible that de novo synthesis of PC continues unabated even though lyso $\mathrm{PC}$ is available. In this instance, the data could be explained by assuming that the PC generated by lyso PC acyltransferase is preferentially distributed into a pool from which chylomicron PC is drawn. The present data cannot completely distinguish between these two possibilities.

Bile PC has been suggested as a preferred precursor of chylomicron PC as compared to exogenous PC (33). This suggestion was in part confirmed in the present study when the ${ }^{32} \mathrm{P}$ label is considered. Nevertheless, it is clear that the saturated fatty acids of bile $\mathrm{PC}$ are considerably different than the saturated fatty acids of chylomicron PC suggesting that the former cannot in toto be the precursor of the latter. The data could be explained if the fatty acids of bile PC influenced its intramucosal pool of distribution such that it would be more likely than potato $\mathrm{PC}$ to enter into the chylomicron PC precursor pool(s). In support of this theory, it should be noted that in the experiment in which bile and potato PC were infused ( $2 \mathrm{mM}$ each), it is estimated that $22 \%$ of the potato PC and only $14.8 \%$ of the bile PC contained stearate (distearoyl PC is unlikely) (25). Were the stearoyl group the only influence on the pathway of distribution into chylomicron PC, the observed ${ }^{32} \mathrm{P}:{ }^{14} \mathrm{C}$ ratio should have been 0.67 . In fact, this ratio was $1.5: 1$.

The lymph subnate had a reduced PC specific activity whether de novo or PC synthesized from lyso PC is considered. This data in terms of PC synthesized from lyso PC confirms the report of Scow et al. (6). The current data suggest that PC synthesized from either pathway is preferentially distributed into the chylomicron PC precursor pool as compared to the subnatant pool and that these two pools are different. This would raise the speculation that the PC in the subnate comes from PC pools thus far unaccounted for such as the plasma or cellular membrane.

\section{ACKNOWLEDGMENTS}

Marcia Steere, Murphy Jenkins and Mary Brown gave expert technical assistance.

This work was supported in part by National Institutes of Health Research grant 5-R01 AM 17526 and by Veterans Administration grant 5438-02.

\section{REFERENCES}

1. Zilversmit, D. B. 1965. The composition and structure of lymph chylomicrons in dog, rat, and man. J. Clin. Invest. 44: 1610-1622.

2. Hofmann, A. F., and D. M. Small. 1967. Detergent properties of bile salts: Correlation with physiological function. Annu. Rev. Med. 18: 333-376.

3. Sabesin, S. M., P. R. Holt, and S. B. Clark. 1975. Intestinal lipid absorption: Evidence for an intrinsic defect of chylomicron secretion by normal rat distal intestine. Lipids. 10: 840-846.

4. Gurr, M. I., W. F. R. Pover, J. N. Hawthorne, and A. C. Frazer. 1963. The phospholipid composition and turnover in rat intestinal mucosa during fat absorption. In Biochemical Problems of Lipids. A. C. Frazer, editor. Elsevier Nederland, Amsterdam. 236-243.

5. Noma, A. 1964. Studies on the phospholipid metabolism of the intestinal mucosa during fat absorption. $J$. Biochem. (Tokyo). 56: 522-532.

6. Scow, R. O., Y. Stein, and O. Stein. 1967. Incorporation of dietary lecithin and lysolecithin into lymph chylomicrons in the rat. J. Biol. Chem. 242: 4919-4924.

7. Nilsson, A. 1968. Intestinal absorption of lecithin and lysolecithin by lymph fistula rats. Biochim. Biophys. Acta. 152: 379-390.

8. Mansbach, C. M., II. 1973. Complex lipid synthesis in hamster intestine. Biochim. Biophys. Acta. 296: 386400.

9. Mansbach, C. M., II. 1975. Effect of fat feeding on complex lipid synthesis in hamster intestine. Gastroenterology. 68: 708-714.

10. Mansbach, C. M., II. 1975. Effect of acute dietary alteration upon intestinal lipid synthesis. Lipids. 10: 318-321.

11. Mansbach, C. M. 1976. Intramicrosomal location in intestine of enzymes which synthesize complex lipid. Enzyme (Basel). 21: 137-141.

12. Ashworth, C. T., and J. M. Johnston. 1963. The intestinal absorption of fatty acid: A biochemical and electron microscopic study. J. Lipid Res. 4: 454-460.

13. Warshaw, A. L. 1972. A simplified method of cannulating the intestinal lymphatic of the rat. Gut. 13: 66-67.

14. Folch, J., M. Lees, and G. H. Sloan Stanley. 1957. A simple method for the isolation and purification of total lipids from animal tissues. J. Biol. Chem. 226: 497-509.

15. Mansbach, C. M., II, R. S. Cohen, and P. B. Leff. 1975. Isolation and properties of the mixed lipid micelles present in intestinal content during fat digestion in man. J. Clin. Invest. 56: 781-791.

16. Snyder, F., and N. Stephens. 1959. Simplified spectrophotometric determination of ester groups in lipids. Biochim. Biophys. Acta. 34: 244-245. 
17. Beroza, M., and B. A. Bierl. 1967. Rapid determination of olefin position in organic compounds in microgram range by ozonolysis and gas chromatography. Alkylidene analysis. Anal. Chem. 39: 1131-1135.

18. Mansbach, C. M., II. 1972. Lysolecithin acyltransferase in hamster intestinal mucosa. Lipids. 7: 593-595.

19. Galliard, T. 1972. A simple biochemical method for the preparation of high specific activity $\left[{ }^{14} \mathrm{C}\right]$ acyl-labelled phosphatidylcholine and other phospholipids. Biochim. Biophys. Acta. 260: 541-546.

20. Lea, C. H., D. N. Rhodes, and R. D. Stoll. 1955. Phospholipids. III. The chromatographic separation of glycerophospholipids.' Biochem. J. 60: 353-363.

21. Bligh, E. G., and W. J. Dyer. 1959. A rapid method of total lipid extraction and purification. Can. J. Biochem. Physiol. 37: 911-917.

22. Clark, S. B., B. Lawergren, and J. V. Martin. 1973. Regional intestinal absorptive capacities for triolein: An alternative to markers. Am. J. Physiol. 225: 574-585.

23. Clark, S. B. 1971. The uptake of oleic acid by rat small intestine: A comparison of methodologies. J. Lipid Res. 12: $43-55$.

24. Clark, S. B. 1976. Chylomicron composition and triglyceride transport rate. Gastroenterology. 70: 871 . (Abstr.)

25. Menzel, D. B., and H. S. Olcott. 1964. Positional distribution of fatty acids in fish and other animal lecithins. Biochim. Biophys. Acta. 84: 133-139.

26. Senior, J. R. 1964. Intestinal absorption of fats. J. Lipid Res. 5: 495-521.

27. Saunders, D. R., P. O. Ways, C. M. Parmentrei, and C. E. Rubin. 1966. Studies on the lipid composition of human small bowel mucosa. J. Clin. Invest. 45: 1516-1525.

28. Whyte, M., D. S. Goodman, and A. Karmen. 1965. Fatty acid esterification and chylomicron formation during fat absorption in rat: III. Positional relations in triglycerides and lecithin. J. Lipid Res. 6: 233-240.

29. Weiss, S. B., S. W. Smith, and E. P. Kennedy. 1958. The enzymatic formation of lecithin from cytidine diphosphate choline and D-1,2 diglyceride. J. Biol. Chem. 231: 53-64.
30. Gurr, M. I., D. N. Brindley, and G. Hübscher. 1965. Metabolism of phospholipids. VIII. Biosynthesis of phosphatidylcholine in the intestinal mucosa. Biochim. Biophys. Acta. 98: 486-501.

31. Lands, W. E. M. 1960. Metabolism of glycerolipids: II. The enzymatic acylation of lysolecithin. J. Biol. Chem. 235: 2233-2237.

32. Subbaiah, P. V., P. S. Sastry, and J. Ganguly. 1969. Acylation of lysolecithin to lecithin by a brush-border-free particulate preparation from rat intestinal mucosa. Biochem. J. 113: 441-442.

33. Ng, P. Y., and P. R. Holt. 1974. Sources of chylomicron phospholipid. Clin. Res. 22: 695A. (Abstr.)

34. Stein, Y., and O. Stein. 1966. Metabolism of labeled lysolecithin, lysophosphatidyl ethanolamine and lecithin in the rat. Biochim. Biophys. Acta. 116: 95-107.

35. Minari, O., and D. B. Zilversmit. 1963. Behavior of dog lymph chylomicron lipid constituents during incubation with serum. J. Lipid Res. 4: 424-436.

36. Treble, D. H., S. Frumkin, J. A. Balint, and D. A. Beeler. 1970. The entry of choline into lecithin, in vivo, by base exchange. Biochim. Biophys. Acta. 202: 163-171.

37. Sundler, R., and B. Åkesson. 1975. Regulation of phospholipid biosynthesis in isolated rat hepatocytes. Effect of different substrates. J. Biol. Chem. 250: 3359-3367.

38. Weinhold, P. A., R. S. Skinner, and R. D. Saunders. 1973. Activity and some properties of choline kinase, cholinephosphate cytidyltransferase and choline phosphotransferase during development in the rat. Biochim. Biophys. Acta. 326: 43-51.

39. Fallon, H. J., J. Barkwick, R. G. Lamb, and H. van den Bosch. 1975. Studies of rat liver microsomal diglyceride acyltransferase and cholinephosphotransferase using microsomal-bound substrate: Effect of high fructose intake. J. Lipid Res. 16: 107-115.

40. Kanoh, H., and K. Ohno. 1973. Utilization of endogenous phospholipids by the backreaction of CDP-choline (-ethanolamine): 1,2 diglyceride choline (ethanolamine)phosphotransferase in rat liver microsomes. Biochim. Biophys. Acta. 306: 203-217. 